\title{
ANALISIS PENGARUH GAYA KEPEMIMPINAN DAN MOTIVASI TERHADAP KINERJA KARYAWAN DEPARTEMEN PENJUALAN DI PT.SUMBERMULIA HASILGUNA JAKARTA
}

\author{
Carolus Lwanga Tindra Matutino Kinasih \\ STIE Unisadhuguna Jakarta, Indonesia \\ Email : carolus.kinasih@gmail.com
}

\begin{abstract}
Abstrak
Pendahuluan : Kemampuan suatu perusahaan untuk berkembang sangat bergantung pada kemampuan sumber daya manusia dalam memanfaatkan sumber daya yang ada di perusahaan. Keberhasilan seluruh pelaksanaan tugas-tugas kerja suatu perusahaan sangat ditentukan oleh tersedianya sumber daya manusia yang berkualitas.

Tujuan : Penelitian ini bertujuan untuk meneliti dan menganalisis pengaruh gaya kepemimpinan dan motivasi terhadap kinerja karyawan di PT Sumbermulia Hasilguna Jakarta.

Metode : Data yang dikumpulkan melalui distribusi kuesioner dan diimplementasikan kepada 58 karyawan PT Sumbermulia Hasilguna Jakarta. Analisis data dalam penelitian ini menggunakan bantuan SPSS versi 20. Teknik sampling menggunakan metode sensus dan teknik tes data yang digunakan dalam penelitian termasuk uji validitas berdasarkan analisis faktor, uji keandalan dengan cronbach. Tes asumsi klasik dan analisis regresi linier yang berlipat ganda, untuk memverifikasi dan membuktikan hipoteis penelitian.
\end{abstract}

Hasil : Hasil analisis menunjukkan bahwa gaya kepemimpinan tidak memiliki pengaruh positif terhadap kinerja dan motivasi karyawan memiliki pengaruh positif terhadap kinerja karyawan.

Kesimpulan : Namun, berdasarkan hasil tes yang dilakukan oleh tes simultan (F test) menunjukkan bahwa variabel gratis secara keseluruhan Leadership Style (X1) dan Motivation (X2) bersama-sama memiliki pengaruh yang signifikan terhadap Kinerja Karyawan. Nilai R Square adalah 0,579, yang berarti bahwa Gaya Kepemimpinan (X1) dan Motivasi (X2) bersama-sama mampu menjelaskan variabel Kinerja Karyawan sama dengan 57,9\% sedangkan sisanya sama dengan $42,1 \%$ adalah variabel yang tidak diusulkan dalam penelitian ini.

Kata kunci : Gaya Kepemimpinan, Motivasi, dan Kinerja Karyawan

\section{Abstract}

Introduction: The ability of a company to develop depends heavily on the ability of human resources in utilizing existing resources in the company. The success of the entire implementation of a company's work tasks is largely determined by the availability of quality human resources. 
Objective: This research aims to research and analyze the influence of leadership styles and motivations on employee performance at PT Sumbermulia Hasilguna Jakarta.

Method: Data collected through questionnaire distribution and implemented to 58 employees of PT Sumbermulia Hasilguna Jakarta. The data analysis in this study used the help of SPSS version 20. Sampling techniques using census methods and data test techniques used in the study included validity tests based on factor analysis, reliability tests with cronbach. Classical assumption tests and linear regression analysis are multiplied, to verify and prove the hypothesis of the study.

Results: The results of the analysis showed that leadership styles did not have a positive influence on employee performance and motivation had a positive influence on employee performance.

Conclusion: However, based on the results of tests conducted by simultaneous tests ( $F$ tests) showed that the overall free variables Leadership Style (X1) and Motivation (X2) together had a significant influence on Employee Performance. Square's $R$ value is 0.579, which means that Leadership Style (X1) and Motivation (X2) are together able to explain employee performance variables equal to $57.9 \%$ while the rest equals $42.1 \%$ are variables not proposed in the study.

Keywords: Leadership Style, Motivation, and Employee Performance.

\section{Pendahuluan}

Melihat perubahan lingkungan organisasi yang semakin kompleks dan kompetitif, mensyaratkan perusahaan untuk bersikap lebih responsif agar tetap bertahan. Setiap organisasi dituntut untuk siap menghadapi perkembangan teknologi (Andi, Nuraldy, \& Imbron, 2020) kebutuhan konsumen, dan persaingan yang ketat dengan perusahaan lain. Menurut (Riniwati, 2016) kemampuan suatu perusahaan untuk berkembang sangat bergantung pada kemampuan sumber daya manusia dalam memanfaatkan sumber daya yang ada di perusahaan. Keberhasilan seluruh pelaksanaan tugas-tugas kerja suatu perusahaan sangat ditentukan oleh tersedianya sumber daya manusia yang berkualitas (Khalik, 2013). Dengan dukungan sumber daya manusia yang berkualitas, tentunya diharapkan berperan aktif sebagai perencana, pelaksana sekaligus sebagai pengawas terhadap semua kegiatan manajemen perusahaan (Busro, 2018). Bukan hanya peningkatan kualitas sumber daya manusia, pihak perusahaan dituntut untuk terus meningkatkan daya saingnya melalui peningkatan kualitas manajemen (Adhani, 2013). Oleh karena itu, agar perusahaan dapat berkembang secara optimal, maka pemeliharaan hubungan yang selaras dan secara berkelanjutan dengan para karyawan menjadi sangat penting (Ng \& Daromes, 2016).

Kepemimpinan memiliki hubungan antara manusia, yaitu hubungan mempengaruhi (dari pemimpin) dan hubungan kepatuhan-ketaatan para pengikut (bawahan) karena dipengaruhi oleh kewibawaan pemimpin. Selanjutnya para pengikut terkena pengaruh kekuatan dari pimpinannya dan bangkitlah 
secara spontan rasa ketaatan pada pemimpin (Nizomi, 2019). Konsep gaya menunjukkan bahwa kita berurusan dengan kombinasi bahasa dan tindakan, yang tampaknya menggambarkan suatu pola yang cukup konsisten. Pola Bahasa dan tindakan yang bagaimana, yang dapat digunakan seseorang untuk membantu orang lain mencapai hasil yang diinginkan. Tanpa mempertimbangkan suatu cara pandang tertentu, beberapa pendekatan yang berbeda meliputi : (1) mengendalikan atau mengarahkan orang lain, (2) memberi tantangan atau angsangan kepada orang lain, (3) menjelaskan kepada atau memberi instruksi kepada orang lain, (4) mendorong atau mendukung orang lain, (5) memohon atau membujuk orang lain, (6) melibatkan atau memberdayakan orang lain, dan (7) memberi ganjaran atau memperkuat orang lain (Yudiaatmaja, 2013).

Dalam perkembanganya, melakukan penilaian kinerja pegawai tidaklah sederhana. Karena dalam penilaian kinerja memerlukan syarat, indikator, serta terdapat elemen-elemen atau variabel-variabel yang mempengaruhinya.. Adapun beberapa variabel yang dapat mempengaruhi kinerja karyawan adalah Gaya kepemimpinan, gaya kepemimpinan yang biasa diterapkan pimpinan kepada bawahan atau pegawai dalam rangka proses kepemimpinannya, dan Motivasi kerja, motivasi kerja yang biasa diberikan pemimpin atau organisasi kepada bawahan atau pegawai.

Penelitian ini sejalan dengan yang dibuat oleh (Ato'illah, 2014) dalam penelitian sebelumnya diungkapkan bahwa perlunya ditingkatkan perhatian dan kebijakan terhadap pegawai kelurahan mengenai kinerja, menyangkut standar waktu yang masih dapat dikatakan kurang serta harus di ciptakan pemberian motivasi terhadap pegawai yang baik untuk bisa tercapainya tujuan organisasi. Penelitian lainnya diungkapkan oleh (ABDILAH \& Djastuti, 2011) dengan hasil bahwasanya hasil analisis data, maka persamaan regresi yang didapat adalah sebagai berikut: $\mathrm{Y}=0,465 \mathrm{X} 1+0,398 \mathrm{X} 2$ Hasil dari uji $t$, gaya kepemimpinan dan motivasi kerja berpengaruh positif dan signifikan terhadap kinerja pegawai. Hasil secara simultan dengan uji $\mathrm{F}$ menunjukkan bahwa semua variabel independen berpengaruh signifikan tehadap kinerja pegawai. Nilai koefisien determinasi (R2) sebesar 0,680 yang menunjukkan bahwa 68\% variabel kinerja pegawai dapat dijelaskan oleh variabel independen gaya kepemimpinan dan motivasi kerja, sedangkan sisanya sebesar $32 \%$ dijelaskan oleh variabel lain.

\section{Metode Penelitian}

Metode yang digunakan dalam penelitian ini adalah metode deskriptif kuantitatif, Metode kuantitatif adalah ilmu dan seni yang berkaitan dengan tata cara (metode) pengumpulan data, analisis data, dan interprestasi hasil analisis untuk mendapatkan informasi dan pengambilan keputusan (Rukajat, 2018). Penelitian ini akan melakukan survey dengan menggunakan alat kuesioner sebagai instrumen pengumpulan data dan hasil dari kuesioner tersebut akan diolah dengan software SPSS versi 20 (Santoso, 2014).

Populasi dalam penelitian ini adalah seluruh karyawan PT Sumbermulia Hasilguna departemen penjualan retail Jakarta sebanyak 58 karyawan. Dalam penelitian 
tidak menggunakan teknik sampling karena sampel yang diteliti adalah keseluruhan dari populasi yang ada atau disebut sensus (Kania Sabariah, 2013).

Pengumpulan data merupakan salah satu kegiatan yang dilakukan dalam proses penelitian. Dalam suatu penelitian ilmiah metode pengumpulan data dimaksudkan untuk memperoleh bahan-bahan yang relevan, akurat, dan terpercaya (Jannah, 2019). Adapun teknik pengumpulan data dengan melalui pengamatan (observasi), studi pustaka, dan angket (quetionary) (Nasehudin \& Gozali, 2012). Selain itu juga digunakan metode pengumpulan data sekunder yaitu dengan metode dokumentasi.

Tabel 1 Definisi Variabel Operasional

\begin{tabular}{|c|c|c|}
\hline Variabel & Konsep Variabel & Indikator \\
\hline $\begin{array}{l}\text { Gaya Kepemimpinan } \\
\text { Demokratis (X1) }\end{array}$ & $\begin{array}{l}\text { Suatu cara pemimpin untuk } \\
\text { mempengaruhi } \\
\text { bawahannya,agar } \\
\text { bekerja secara produktif } \\
\text { untuk mencapai tujuan } \\
\text { organisasi } \\
\text { Hasibuan }(2007: 170)\end{array}$ & $\begin{array}{l}\text { 1. Pengambilan Keputusan } \\
\text { 2. Perilaku Pemimpin } \\
\text { 3. Orientasi kepemimpinan }\end{array}$ \\
\hline Motivasi (X2) & $\begin{array}{l}\text { Motivasi merupakan faktor } \\
\text { psikologis yang menunjukan } \\
\text { minat individu terhadap } \\
\text { pekerjaan, rasa puas dan ikut } \\
\text { bertanggung jawab terhadap } \\
\text { aktivitas atau pekerjaan yang } \\
\text { dilakukan (Masrukhin dan } \\
\text { Waridin, 2004). }\end{array}$ & $\begin{array}{l}\text { 1. Fisiologis, } \\
\text { 2. Keamanan, } \\
\text { 3. Sosial } \\
\text { 4. Penghargaan } \\
\text { 5. Aktualisasi diri. }\end{array}$ \\
\hline $\begin{array}{lll}\text { Kinerja } & \text { Karyawan } & (\mathrm{Y}) \\
\text { Kinerja } & & \end{array}$ & $\begin{array}{l}\text { Kinerja pegawai menurut } \\
\text { Dessler (2006) kinerja } \\
\text { pegawai merupakan prestasi } \\
\text { kerja, yakni perbandingan } \\
\text { antara hasil kerja yang dapat } \\
\text { dilihat secara nyata dengan } \\
\text { standar kerja yang telah } \\
\text { ditetapkan perusahaan }\end{array}$ & $\begin{array}{l}\text { 1. Kualitas } \\
\text { 2. Kuantitas } \\
\text { 3. Ketepatan waktu } \\
\text { 4. Efektifitas } \\
\text { 5. Kemandirian }\end{array}$ \\
\hline
\end{tabular}

\section{Hasil dan Pembahasan}

1. Uji Validitas

Tabel 2

Uji Validitas Variabel Gaya Kepemimpinan (X1)

Pernyataan Gaya Kepemimpinan $(\mathrm{X} 1)$




\begin{tabular}{cccc}
\hline & rhitung & rtabel & Keterangan \\
\hline GK1 & $.568^{* *}$ & 0.258 & Valid \\
\hline GK2 & $.732^{* *}$ & 0.258 & Valid \\
\hline GK3 & $.490^{* *}$ & 0.258 & Valid \\
\hline GK4 & $.578^{* *}$ & 0.258 & Valid \\
\hline GK5 & $.320^{*}$ & 0.258 & Valid \\
\hline GK6 & $.286^{*}$ & 0.258 & Valid \\
\hline GK7 & $.261^{*}$ & 0.258 & Valid \\
\hline GK8 & $.608^{* *}$ & 0.258 & Valid \\
\hline GK & 1 & 0.258 & Valid \\
\hline Sumber: &
\end{tabular}

Sumber: Data primer diolah, 2017.

Berdasarkan tabel uji validitas diatas menunjukan korelasi antara masingmasing pernyataan terhadap total skor konstruk dari variabel gaya kepemimpinan (X2) menunjukan hasil yang signifikan, dan menunjukkan bahwa $r$ hitung $>r$ tabel yaitu $>0.258$. sehingga dapat disimpulkan bahwa semua item pernyataan variabel gaya kepemimpinan dinyatakan valid.

\section{Tabel 4}

\section{Uji Validitas Variabel Motivasi (X2)}

\begin{tabular}{llll}
\hline \multirow{2}{*}{ Pernyataan } & \multicolumn{3}{c}{ Motivasi (X2) } \\
\cline { 2 - 4 } & R Hitung & R Tabel & Keterangan \\
\hline M1 & $.580^{* *}$ & 0.258 & Valid \\
\hline M2 & $.608^{* *}$ & 0.258 & Valid \\
\hline M3 & $.440^{* *}$ & 0.258 & Valid \\
\hline M4 & $.441^{* *}$ & 0.258 & Valid \\
\hline M5 & $.280^{*}$ & 0.258 & Valid \\
\hline M6 & $.385^{*}$ & 0.258 & Valid \\
\hline M7 & $.275^{*}$ & 0.258 & Valid \\
\hline M8 & $.397^{* *}$ & 0.258 & Valid \\
\hline M9 & $.419^{* *}$ & 0.258 & Valid \\
\hline M10 & $.513^{* *}$ & 0.258 & Valid \\
\hline M & 1 & 0.258 & Valid \\
\hline
\end{tabular}

Sumber: Data primer diolah, 2017.

Berdasarkan tabel uji validitas diatas menunjukan korelasi antara masingmasing pernyataan terhadap total skor konstruk dari variabel motivasi (X2) menunjukan hasil yang signifikan, dan menunjukkan bahwa $\mathrm{r}$ hitung $>\mathrm{r}$ tabel yaitu $>$ 0.258. sehingga dapat disimpulkan bahwa semua item pernyataan variabel motivasi dinyatakan valid.

Tabel 5

Uji ValiditasKinerja Karyawan (Y)

Kinerja Karyawan

(Y)

\begin{tabular}{llll} 
& Rhitung & Rtabel & Keterangan \\
\hline KK1 & $.771^{* *}$ & 0.258 & Valid \\
\hline
\end{tabular}




\begin{tabular}{llll}
\hline KK2 & $.765^{* *}$ & 0.258 & Valid \\
\hline KK3 & $.446^{* *}$ & 0.258 & Valid \\
\hline KK4 & $.531^{* *}$ & 0.258 & Valid \\
\hline KK5 & $.499^{*}$ & 0.258 & Valid \\
\hline KK6 & $.530^{*}$ & 0.258 & Valid \\
\hline KK7 & $.416^{*}$ & 0.258 & Valid \\
\hline KK8 & $.682^{* *}$ & 0.258 & Valid \\
\hline KK9 & $.719^{* *}$ & 0.258 & Valid \\
\hline KK10 & $.371^{* *}$ & 0.258 & Valid \\
\hline KK11 & $.685^{* *}$ & 0.258 & Valid \\
\hline \multicolumn{4}{c}{ Sumber: Data primer diolah, 2017. }
\end{tabular}

Berdasarkan tabel uji validitas diatas menunjukan korelasi antara masingmasing pernyataan terhadap total skor konstruk dari variable kinerja karyawan (Y) menunjukan hasil yang signifikan, dan menunjukkan bahwa $\mathrm{r}$ hitung $>\mathrm{r}$ tabel yaitu $>$ 0.258. sehingga dapat disimpulkan bahwa semua item pernyataan variabel kinerja karyawan dinyatakan valid.

\section{Uji Realibilitas}

Tabel 6

Hasil Uji Reliabilitas

\begin{tabular}{rrr}
\hline \multirow{2}{*}{ Variabel } & \multicolumn{2}{c}{ Reliability Statistics } \\
\cline { 2 - 3 } & $\begin{array}{c}\text { Cronbach's } \\
\text { Alpha }\end{array}$ & $\begin{array}{c}\text { N of } \\
\text { Items }\end{array}$ \\
\hline GK & 0.697 & 9 \\
\hline M & 0.688 & 11 \\
\hline K & 0.747 & 12 \\
\hline
\end{tabular}

Sumber: Data primer diolah, 2017

Dari tabel hasil uji reliabilitas menunjukkan bahwa variabel gaya kepemimpinan (X1) mempunyai koefisien alpha sebesar 0,697. Variabel Motivasi (X2) mempunyai koefisien alpha sebesar 0,688. Sedangkan variabel kinerja karyawan (Y) mempunyai koefisien alpha sebesar 0,747. Semua koefisien alpha dari masing-masing variabel yaitu diatas 0,60. Sehingga dapat dikatakan konsep pengukuran adalah reliabel.

\section{Uji Asumsi Klasik}

\section{a. Uji Multikolinearitas}

Tabel 7 Hasil Uji Multikolinearitas

\begin{tabular}{llll}
\hline \multirow{2}{*}{ Model } & \multicolumn{2}{c}{ Collinearity Statistics } \\
\cline { 2 - 4 } & & Tolerance & VIF \\
\hline \multirow{2}{*}{1} & (Constant) & & \\
\cline { 2 - 4 } & GK & .667 & 1.500 \\
\hline
\end{tabular}




\begin{tabular}{crr}
\hline M & .667 & 1.500 \\
\hline Sumber: Data primer diolah, 2017
\end{tabular}

Berdasarkan tabel hasil uji multikolinearitas menunjukkan bahwa nilai VIF semua variabel bebas dalam penelitian ini lebih kecil dari 10 sedangkan nilai toleransi semua variabel bebas lebih dari $10 \%$ yang berarti tidak terjadi korelasi antara variabel bebas yang nilainya lebih dari 90\%. Dengan demikian dapat disimpulkan bahwa tidak terjadi gejala multikolinearitas antar variabel bebas dalam model regresi.

\section{b. Uji Heteroskedastisitas}

Uji heteroskedastitas menunjukan bahwa nilai signifikansi variabel gaya kepemimpinan sebesar 0.723 yaitu lebih besar dari 0.005 , artinya tidak ada heteroskedastitas pada variabel gaya kepemimpinan (X1). Sementara itu nilai signifikansi dari variabel Motivasi adalah 0.081 lebih besar dari 0,05, artinya tidak terjadi heteroskedastitas pada variabel motivasi (X2).

\section{c. Uji Normalitas}

\section{Tabel 8}

Hasil Uji Normalitas

\begin{tabular}{|c|c|c|}
\hline \multicolumn{3}{|c|}{ One-Sample Kolmogorov-Smirnov Test } \\
\hline \multirow{2}{*}{\multicolumn{3}{|c|}{$\begin{array}{c}\text { Unstandardized } \\
\text { Residual }\end{array}$}} \\
\hline & & \\
\hline $\mathrm{N}$ & & 58 \\
\hline \multirow{3}{*}{$\begin{array}{c}\text { Normal } \\
\text { Parameters }\end{array}$} & Mean & 0E-7 \\
\hline & Std. & 2.73974463 \\
\hline & Deviation & \\
\hline \multirow{3}{*}{$\begin{array}{l}\text { Most Extreme } \\
\text { Differences }\end{array}$} & Absolute & .142 \\
\hline & Positive & .142 \\
\hline & Negative & -.134 \\
\hline \multicolumn{2}{|c|}{ Kolmogorov-Smirnov Z } & 1.080 \\
\hline \multicolumn{2}{|c|}{ Asymp. Sig. (2-tailed) } & .194 \\
\hline \multicolumn{3}{|c|}{ a. Test distribution is Normal. } \\
\hline
\end{tabular}

Dari tabel uji Normalitas, diketahui bahwa nilai siignifikansi sebesar 0.194 yaitu lebih besar dari 0.05 , artinya bahwa data yang diuji berdistribusi normal.

\section{Analisis Regresi Linear Berganda}

Tabel 9

Hasil Uji Regresi Linear Berganda

\begin{tabular}{|c|c|}
\hline Model & $\begin{array}{l}\text { Unstandardized } \\
\text { Coefficients }\end{array}$ \\
\hline & Std. Error \\
\hline
\end{tabular}




\begin{tabular}{|c|c|c|c|c|}
\hline (Constant) & 1.961 & 5.247 & .374 & .710 \\
\hline $1 \mathrm{GK}$ & .230 & .148 & 1.553 & .126 \\
\hline M & .871 & .143 & 6.090 & .000 \\
\hline
\end{tabular}

Untuk menentukan nilai persamaan regresi linear berganda sebagai berikut:

$$
Y=1,961+0,166 \times 1+0,653 \times 2
$$

Dari persamaan tersebut dapat dijelaskan sebagai berikut :

1) Nilai konstanta intersep sebesar 1,961 menyatakan bahwa jika variabel gaya kepemimpinan dan variabel motivasi tetap, maka nilai variabel kinerja karyawan akan menurun sebesar 1,961.

2) Variabel gaya kepemimpinan dan motivasi mempunyai arah koefisien yang bertanda positif terhadap kinerja karyawan.

3) Koefisien gaya kepemimpinan memberikan nilai sebesar 0,166 yang berarti bahwa jika gaya kepemimpinan semakin baik dengan asumsi variabel lain tetap maka kinerja karyawan akan mengalami peningkatan.

4) Koefisien motivasi memberikan nilai sebesar 0,653 yang berarti jika kinerja karyawan semakin kuat dengan asumsi variabel lain tetap maka kinerja karyawan akan mengalami peningkatan.

\section{Pengujian Hipotesis Simultan (Uji F)}

Tabel 10 Uji Hipotesis Simultan (Uji F)

\begin{tabular}{|c|c|c|c|c|c|}
\hline \multicolumn{6}{|c|}{ ANOVA $^{a}$} \\
\hline Model & $\begin{array}{l}\text { Sum of } \\
\text { Squares }\end{array}$ & & $\begin{array}{l}\text { Mean } \\
\text { Square }\end{array}$ & $\mathrm{F}$ & Sig. \\
\hline Regression & 588.371 & 2 & 294.185 & 37.817 & $.000^{\mathrm{b}}$ \\
\hline 1 Residual & 427.853 & 55 & 7.779 & & \\
\hline Total & 1016.224 & 57 & & & \\
\hline \multicolumn{6}{|c|}{ a. Dependent Variable: KK } \\
\hline \multicolumn{6}{|c|}{ b. Predictors: (Constant), M, GK } \\
\hline
\end{tabular}

Sumber: Data primer diolah, 2017

Pengujian pengaruh variabel bebas secara bersama-sama terhadap variabel terikatnya dilakukan dengan menggunakan uji F. Hasil perhitungan statistik menunjukkan nilai F hitung $=37,817$. Dengan menggunakan batas signifikansi 0.05 , maka diperoleh nilai signifikansi tersebut lebih kecil dari 0,05 yaitu 0,000. Hal ini dapatdiartikan bahwa hipotesis yang menyatakan bahwa secara simultan variabel gaya kepemimpinan dan motivasi secara bersamaan mempunyai pengaruh positif terhadap kinerja karyawan.

6. Uji Koefisien Determinasi $\mathbf{r}^{2}$

Tabel 11

Hasil Uji Koefisien Determinasi $\mathrm{r}^{2}$ Model Summary ${ }^{b}$ 


\begin{tabular}{lccrr}
\hline Model & R & R Square & Adjusted R Square & Std. Error of the Estimate \\
\hline 1 & $.761^{\mathrm{a}}$ & .579 & .564 & 2.789 \\
\hline a. Predictors: (Constant), M, GK & & \\
\hline
\end{tabular}

Sumber: Data primer diolah, 2017

Hasil perhitungan regresi dapat diketahui bahwa koefisien determinasi (R2) yang diperoleh sebesar 0,579 . Hal ini berarti 57,9\% variasi variabel kinerja karyawan dapat dijelaskan oleh variable gaya kepemimpinan dan motivasi. Sedangkan sisanya sebesar $42,1 \%$ diterangkan oleh variabel lain yang tidak diajukan pada penelitian ini.

\section{Uji Hipotesis secara Parsial (Uji t)}

\section{Tabel Hasil Uji Hipotesis Secara Parsial (Uji t)}

\begin{tabular}{|c|c|c|c|c|c|c|c|}
\hline \multicolumn{8}{|c|}{ Coefficients $^{\mathbf{a}}$} \\
\hline \multirow[t]{2}{*}{ Model } & \multicolumn{2}{|c|}{$\begin{array}{l}\text { Unstandardized } \\
\text { Coefficients }\end{array}$} & $\begin{array}{l}\text { Standardized } \\
\text { Coefficients }\end{array}$ & \multirow[t]{2}{*}{$\mathrm{T}$} & \multirow[t]{2}{*}{ Sig. } & \multicolumn{2}{|c|}{$\begin{array}{l}\text { Collinearity } \\
\text { Statistics }\end{array}$} \\
\hline & B & Std. Error & Beta & & & Tolerance & VIF \\
\hline 1 (Constant) & 1.961 & 5.247 & & .374 & .710 & & \\
\hline GK & .230 & .148 & .166 & 1.553 & .126 & .667 & 1.500 \\
\hline $\mathrm{M}$ & .871 & .143 & .653 & 6.090 & .000 & .667 & 1.500 \\
\hline
\end{tabular}

\section{a. Uji Hipotesis 1 (H1)}

Perumusan Hipotesis:

$\mathrm{Ha}$ : Terdapat Pengaruh positif antara gaya kepemimpinan terhadap kinerja karyawan

Ho : Tidak terdapat pengaruh positif antara gaya kepemimpinan terhadap kinerja karyawan

Berdasarkan tabel uji hipotesis secara parsial terlihat hasil pengujian hipotesis gaya kepemimpinan menunjukan nilai t hitung sebesar 1,553 dengan taraf signifikan sebesar 0,126. Dengan taraf signifikan tersebut lebih besar dari 0,05, yang artinya bahwa Ho untuk gaya kepemimpinan ditolak. Dengan demikian dapat diartikan bahwa Hipotesis H1" Gaya kepemimpinan tidak mempunyai pengaruh signifikan terhadap kinerja karyawan departemen penjulan PT Sumbermulia Hasilguna Jakarta"

\section{b. Uji Hipotesis 2 (H2)}

Berdasarkan dari tabel diatas terlihat hasil pengujian hipotesis gaya kepemimpinan menunjukan nilai t hitung sebesar 6,090 dengan taraf signifikan sebesar 0,000. Dengan taraf signifikan tersebut lebih kecil dari 0,05, yang artinya bahwa Ha untuk motivasi diterima dan Ho motivasi ditolak. Dengan demikian dapat diartikan bahwa Hipotesis H2" Motivasi mempunyai pengaruh 
signifikan terhadap kinerja karyawan departemen penjulan PT Sumbermulia Hasilguna Jakarta"

\section{c. Uji Hipotesis 3 (H3)}

Berdasarkan dari tabel uji hipotesis secara parsial terlihat hasil pengujian hipotesis yang dilakukan bersamaan oleh variabel gaya kepemimpinan dan miotivasi menunjukan nilai signifikan sebesar 0,000. Dengan signifikan tersebut lebih kecil dari 0,05 , yang artinya bahwa Ha untuk gaya kepemimpinan dan motivasi diterima dan Ho gaya kepemimpinan dan motivasi ditolak. Dengan demikian dapat diartikan bahwa Hipotesis H3" gaya kepemimpinan dan motivasi mempunyai pengaruh positif terhadap kinerja karyawan departemen penjulan PT Sumbermulia Hasilguna Jakarta”

\section{Kesimpulan}

Hubungan variabel gaya kepemimpinan (X1) dengan kinerja karyawan (Y) tidak adanya pengaruh positif dan signifikan. Terlihat dari hasil pengujian hipotesis gaya kepemimpinan menunjukan nilai t hitung sebesar 1,553 dengan taraf signifikan sebesar 0,126 . Dengan taraf signifikan tersebut lebih besar dari 0,05 , yang artinya bahwa Ho untuk gaya kepemimpinan ditolak. Dengan demikian dapat diartikan bahwa Hipotesis H1" Gaya kepemimpinan tidak mempunyai pengaruh signifikan terhadap kinerja karyawan departemen penjulan PT Sumber mulia Hasilguna Jakarta”.

Hubungan Motivasi (X2) dengan kinerja karyawan (Y) menunjukan adanya pengaruh positif dan signifikan. Hal tersebut dapat dilihat dari hasil pengujian hipotesis gaya kepemimpinan menunjukan nilai t hitung sebesar 6,090 dengan taraf signifikan sebesar 0,000. Dengan taraf signifikan tersebut lebih kecil dari 0,05, yang artinya bahwa Ha untuk motivasi diterima dan Ho motivasi ditolak. Dengan demikian dapat diartikan bahwa Hipotesis H2" Motivasi mempunyai pengaruh signifikan terhadap kinerja karyawan departemen penjulan PT Sumbermulia Hasilguna Jakarta”.

Adanya pengaruh positif dan signifikan antara gaya kepemimpinan dan motivasi yang dilakukan bersamaan terhadap kinerja karyawan PT Sumbermulia Hasilguna departemen penjualan Jakarta.

\section{DAFTAR PUSTAKA}

Abdilah, Rokhrnaloka Habsoro, \& Djastuti, Indi. (2011). Analisis Pengaruh Gaya Kepemimpinan Dan Motivasi Kerja terhadap Kinerja Pegawai (Studi pada Pegawai Badan Kesatuan Bangsa Politik dan Perlindungan Masyarakat Provinsi Jawa Tengah). UNDIP: Fakultas Ekonomika dan Bisnis. 
Adhani, Akbar Rizky. (2013). Pengaruh kebutuhan aktualisasi diri dan beban kerja terhadap prestasi kerja karyawan. Jurnal Ilmu Manajemen, 1(4), 1223-1233.

Andi, Dede, Nuraldy, Hafis Laksmana, \& Imbron, Imbron. (2020). Pengaruh Kepemimpinan terhadap Kinerja Karyawan pada PT. Megaprima di Jakarta. Jurnal Ekonomi Efektif, 3(1).

Ato'illah, Mohammad. (2014). Analisis Pengaruh Gaya Kepemimpinan Dan Motivasi Terhadap Kinerja Pegawai Kelurahan Di Kecamatan Lumajang Kabupaten Lumajang. Wiga: Jurnal Penelitian Ilmu Ekonomi, 4(1), 1-18.

Busro, Muhamamad. (2018). Teori-teori manajemen sumber daya manusia. Prenada Media.

Jannah, Lina Miftahul. (2019). Metode penelitian kuantitatif.

Kania Sabariah, Mira. (2013). Teknik Sampling.

Khalik, A. (2013). Perubahan Peran Dan Transformasi Fungsi Sumber Daya Manusia Dalam Mewujudkan Good Corporate Governance Dan Corporate Social Responsibility Pada Iain Sulthan Thaha Syaifuddin Jambi. Al-Fikrah: Jurnal Kependidikan Islam IAIN Sulthan Thaha Saifuddin, 4, 56384.

Nasehudin, Toto Syatori, \& Gozali, Nanang. (2012). Metode penelitian kuantitatif.

Ng, Suwandi, \& Daromes, Fransiskus E. (2016). Peran kemampuan manajerial sebagai mekanisme peningkatan kualitas laba dan nilai perusahaan. Jurnal Akuntansi Dan Keuangan Indonesia, 13(2), 174-193.

Nizomi, Khairin. (2019). Gaya Kepemimpinan Perempuan Dalam Budaya Organisasi. JIPI (Jurnal Ilmu Perpustakaan Dan Informasi), 4(2), 128-149.

Riniwati, Harsuko. (2016). Manajemen Sumberdaya Manusia: Aktivitas Utama dan Pengembangan SDM. Universitas Brawijaya Press.

Rukajat, Ajat. (2018). Pendekatan penelitian kuantitatif: quantitative research approach. Deepublish.

Santoso, Singgih. (2014). Panduan Lengkap SPSS versi 20 edisi revisi. Jakarta: PT. Elex Media Komputindo.

Yudiaatmaja, Fridayana. (2013). Kepemimpinan: Konsep, Teori Dan Karakternya. Media Komunikasi FPIPS, 12(2). 